\title{
The System of Copyright Limitations Under the Marrakesh Treaty (2013) in Light of the TRIPS Standards: The Strengths and Weaknesses
}

\author{
Obsa Teshale Alemu ${ }^{1}$
}

\begin{abstract}
The system of copyright limitations, as sub-set of the copyright system, is so important to guarantee free exploitation of copyrighted materials by users. The prominent standards of these limitations, which widely adopted in international intellectual property multilateral treaties/conventions, are commonly known as threestep test/TST. Accordingly, copyright limitations (1) shall be confined to certain special case-specified and narrow in scope and reach, (2) shall not conflict with normal exploitation of the work, and (3) shall not unreasonably prejudice legitimate interest of the right holder. As one of the copyright limitation systems, the Marrakesh treaty (2013) adopted for exclusive benefits of the blind persons, VIPs and PWPD so as to facilitate access of the published works for these persons. Looking at the treaty from the TRIPS' TST point of view, its strengths are, inter alia, overall declaration that orders a contracting party to comply with the obligations it has, if any, under the TRIPS article 13 (TST) as well as providing specific and clear conditions, under some of its provisions, that presumptively endorsed requirements of the TST. As far as weakness of the system is concerned, whether or not those provisions that already contain conditions presumed as requirements of the TRIPS' TST needed to be tested twice against the TST, which is blurred concept by itself, is unclear. Furthermore, possibility of extending limitations to works that commercial available under reasonable terms as well as making all (or some) of limitations uncompensated, without articulation of clear pre-conditions may violate requirement(s) of the TST. Looking from intended goals perspective, however, strengths of the treaty outweigh its weaknesses. Adoption of copyright limitations for the exclusive benefits of blind persons, VIPs and PWPD, who have starvation of published works/books, undoubtedly counted as a breakthrough. This is great global achievement as to providing innovative copyright limitations or at least clarifying already recognized limitations.
\end{abstract}

Key Terms: TRIPS Standard, Marrakesh Treaty, Copyright Limitations

DOI: $10.7176 / \mathrm{JLPG} / 114-02$

Publication date:October $31^{\text {st }} 2021$

Abbreviations
AFCs
L\&Es
MT
PWPD
TRIPS
TRMs
TST
UNCRPD
VIP

\section{Introduction}

The copyright law was emerged hand in hand with technological evolution, particularly invention of print that highly flourished mass dissemination of information. ${ }^{2}$ Consequently, the Berne Convention for the Protection of Literary and Artistic Works (hereafter 'Berne Convention') that might be taken as pioneer international framework regarding copyright adopted in 1886. Accordingly, the copyright limitations were born, along with exclusive rights of author/right holder, to ensure benefit of copyright users. Then the Agreement on TradeRelated Aspects of Intellectual Property Rights (1994), hereafter 'TRIPS or TRIPS Agreement', sophisticated copyright and its limitations relatively. Still the system of copyright limitations was optional. Particularly there was no direct international obligation on states to enact domestically copyright limitations pertaining to the visually impaired persons before the Marrakesh Treaty to Facilitate Access to Published Works for Persons Who are Blind, Visually Impaired, or otherwise Print Disabled (hereafter 'Marrakesh Treaty'). The Marrakesh Treaty

\footnotetext{
1 He held LL.B from Adama Science and Technology University, Humanities and Law School, in 2015 G.C, and LL.M in Business Law from Addis Ababa University, in 2021 G.C. Formerly he was a Judge of Oromia Woreda/First Instance/ Court and currently Lecturer of Law at Wolkite University, School of Law.

2 Orit Fischman-Afori, 'The Evolution of Copyright Law and Inductive Speculations as to Its Future', (University of Georgia, Journal of Intellectual Property Law, Vol.19 No.2), 233.
} 
was adopted in 2013 but entered into force in 2016.

Under international copyright system, there are prominent standards for copyright limitations that are commonly known as the three-step test. Mainly, the TRIPS Agreement has incorporated these standards. Then, the Marrakesh Treaty that dedicated exclusively to copyright limitations that facilitate access to published works for blind persons, VIPs and PWPD adopted optimistically to redress existing book famine. Under the treaty, there are both specific limitations and general limitations. Hence, divulging strengths and weaknesses of the copyright limitations under the Marrakesh Treaty in light of the TRIPS standards for copyright limitations as well as incidentally glimpsing compatibility of the approach used with the contemplated objectives of the treaty are issues that necessitated this systematic investigation.

The main objective of this article is to normatively analyze strengths and weaknesses of system of copyright limitations under the Marrakesh Treaty for visually impaired, taking the TRIPS standards for copyright limitations as yardsticks. Essentially, the three-step-test of TRIPS Agreement, which is largely fetched from Berne Convention, has been intensively analyzed as TRIPS standards for copyright limitations. Subsequently, these standards were depicted on system of copyright limitations under the Marrakesh Treaty in order to reveal its strengths and weaknesses. This article is doctrinal legal research. Consequently, the primary source of data is multilateral frameworks/conventions, which primarily include the TRIPS Agreement and the Marrakesh Treaty. The secondary source is also books, commentaries, articles, researches etc. The article starts with the TRIPS standards for copyright limitations. Mainly it discusses the overview of the TRIPS Agreement, the notion of copyright limitations and their justifications as well as the three-step test. The second section addresses copyright limitations system under the Marrakesh Treaty along with its strengths and weaknesses. Thus handful weaknesses that need to be reconsidered have been identified on top of a few strengths that are far from being exhaustive. The conclusion and the ways forward are also provided under the last section.

\section{The TRIPS Standards for Copyright Limitations}

\subsection{Overview of the TRIPS Agreement}

Intended to elevate protection and harmonization of intellectual property, particularly that of copyright, TRIPS Agreement is concocted expansively. ${ }^{1}$ TRIPS Agreement, which is concluded in 1994, set genuine foundation of international system of intellectual property protection in general. ${ }^{2}$ In fact, as far as copyright system is concerned, it is not the icebreaker. There is Berne Convention for the Protection of Literary and Artistic Works that was enacted more than a century before, in 1886, and reshaped frequently thereafter. Moreover, TRIPS Agreement has adopted essential parts, substantive provisions, of the Berne Convention. ${ }^{3}$ Nevertheless, this does not lead one to conclude TRIPS is direct replication of the Berne Convention regarding copyright system. '...the earlier multilateral system [the Berne Convention] had lacked, among other things, an overarching set of principled objectives to guide the development of meaningfully balanced international copyright norms. ${ }^{4}$

Article 7 of the TRIPS enshrined general objectives of protection and enforcement of intellectual property rights although terminologically it seems that copyright system is excluded. The objective is that enhancing technological innovation and its transfer/dissemination, adhering mutual advantage of the producers and users in a manner conducive to social and economic welfare and striking a balance between rights and obligations. The phrase 'technological innovation' is more or less compatible for industrial properties than copyright. But we can argue that this is made inadvertently and unforeseeably because the TRIPS Agreement is a wide-ranging document that takes account of both industrial properties and copyright.

Above and beyond, TRIPS comprises principles that shall be observed while member states domestically enact or amend intellectual property laws. ${ }^{5}$ Among others, they may adopt measures necessary to promote the public interest in sectors of vital importance of their socio-economic development as long as the measures do not contravene provisions of the agreement. Akin to other WTO administered multilateral treaties, the TRIPS Agreement embraced non-discrimination obligations, namely, National Treatment and Most-favored-Nation Treatment under articles 3 and 4 respectively. It radically shifted pre-existing view about correlation of intellectual property rights and international trade as well. Unequivocally, it enunciates that intellectual property rights per se are not barriers to legitimate trade. ${ }^{6}$ Explicit dichotomization of idea and expression of idea is another departure. ${ }^{7}$ As going to be discussed next, there are also slight differences between the Berne Convention and the TRIPS Agreement as regards to standards for copyright limitations-three-step test.

\footnotetext{
Meir Perez Pugatch, 'The International Political Economy of Intellectual Property Rights', 131, available at $<$ https://www.researchgate.net/publication/287422058>, accessed on $28 \mathrm{March}, 2020$.

2 Ruth L. Okediji, The International Copyright System: Limitations, Exceptions and Public Interest Considerations for Developing Countries (UNCTAD-ICTSD Project on IPRs and Sustainable Development, Issue Paper No.15), 1.

TRIPS Agreement borrowed, as enshrined under art.9, Articles 1 through 21 of the Berne Convention (1971) and the Appendix thereto.

Ruth L. Okediji (n 3) 1.

TRIPS Agreement, article 8.

ibid, the preamble.

ibid, article $9(2)$
} 


\subsection{The TRIPS Standards for Copyright Limitations \\ 2.2.1 Notion of Copyright limitations}

Copyright limitations are expressed by a variety of terms under different national and international instruments. Some of them are exceptions, exemptions, users' rights, rights of the public, permitted acts and defenses. ${ }^{1}$ Especially limitations and exceptions are frequently used in the Berne Convention and the TRIPS Agreement either interchangeably or in different context. ${ }^{2}$ Prof. Pamela Samuelson noted the difference between limitations and exceptions as follows:

The distinction between "limitations" and "exceptions" is somewhat murky and the two terms are often used interchangeably. "Exceptions" are probably best understood as outright exemptions from copyright liability. "Limitations" is a term that includes compulsory or statutory licenses creating a liability rule, so that acts are permissible but subject to an obligation to pay for the use. ${ }^{3}$

But one may argue that all of these terms concern with acts that users are permitted to do relating to copyrighted works. That means, it is a portion of acts, which might be insignificant or enormous, that left for users to be exploited from entire circle of exclusive right whether freely or with payment but no more monopolized by the right holder. Dr. Biruk has already articulated this clearly saying, '[S]etting aside doctrinal differences, all of these refer to acts the law allows users of copyrighted works to undertake which otherwise would amount to copyright infringement."

Even copyright limitation itself can also be understood from different point of views, such as the subject matter covered, requirements for protection, duration of protection and so on. ${ }^{5}$ But in strict sense of the term, 'copyright' connotes only subject matters covered (works) so long as they fulfill criteria for protection and if their lifespan is not yet over. The rest is public domain that is not eligible to be called as copyright at the outset. 'Limitations on copyrights are an integral part of the copyright system, for they are the recognition in positive law of the users' legitimate interests in making certain unauthorized uses of copyrighted material. ${ }^{6}$ Therefore, it is better to restrict copyright limitations to exclusive rights. Accordingly, this paper focuses only with copyright limitations pertaining to exclusive rights. The reason is that the Marrakesh Treaty, which is to be analyzed taking TRIPS standards as baselines, provides such kind of limitations.

\subsubsection{Justifications for copyright limitations}

There are various justifications for copyright limitations. Ensuring public interest, mitigating the adverse effect of copyright protection on fundamental rights and freedoms, and aiming to cure market dysfunction/failure are typical and sweeping justifications that prevalent in contemporary legal literatures. ${ }^{7}$ Content-wisely, public interest is not uniform throughout the world. '...'public interest' is mostly a matter of national policy: what is in the public interest in one country is not necessarily the same in another. ${ }^{8}$ It is intertwined with the context of each and every country. Mostly exploitation of copyrighted works by libraries, museums, archives, and research and education institutions is justified from public interest point of view. The second justification is essentially about freedom of expression and right to information. Exclusive right of author/holder needs to be reasonably circumvented to ensure such informatory purpose. ${ }^{9}$ Thirdly, some copyright limitations are justified because they intend to rectify market dysfunction or failure. Compulsory license is one of the typical examples. 'Outright exceptions may thus be justifiable to enable some socially desirable uses for which markets cannot effectively and efficiently operate.' ${ }^{\prime 10}$ Meanwhile, regulation of copyright system through limitations is very essential because the market failed to realize desirable outcomes.

\subsubsection{The TRIPS Standards}

As a matter of fact, TRIPS Agreement enunciates international minimum standards for protection of copyright, along with other intellectual property rights. Member states may domestically provide protection that surpasses

\footnotetext{
1 Biruk Haile, 'Scrutiny of the Ethiopian system of Copyright Limitations in the Light of International Legal Hybrid resulting from (the Impending) WTO Membership: Three-Step Test in Focus' (Ethiopian Journal of Law, 2012) 160.

2 The Berne Convention article $2^{\text {bis }}$ is partly titled 'limitation' to express exclusion of works from ambit of copyright. Here 'limitation' is used to indicate what is not protected from the very beginning rather than exception to exclusive right. But it is seemingly used under article 13 to refer exception of exclusive right. 'Exception' is also used under articles 9 and 11 of the Berne convention to denote what is deducted or exempted from exclusive right. On top of incorporating these provisions, via article 9, TRIPS Agreement employs both 'limitations' and 'exceptions' terms under article 13.

3 Pamela Samuelson, 'Justifications for Copyright Limitations \& Exceptions, 1, available at $<$ https://papers.ssrn.com/sol3/papers.cfm?abstract id=2476669>, accessed on 05 April, 2020.

4 Biruk Haile (n 9) 160; see also Ruth L. Okediji (n $\overline{3}$ ) 10-11.

ibid 159.

Dr. Lucie Guibault, 'The Nature and Scope of Limitations and Exceptions to Copyright and Neighboring Rights with regard to General Interest Missions for the Transmission of Knowledge: Prospects to their Adaptation to the Digital Environment', 2, @,

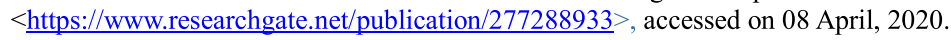

Biruk Haile (n 9) 160; see also Pamela Samuelson (n 11) 10-26.

Dr. Lucie Guibault (n 14) 2.

ibid 6.

Pamela Samuelson (n 11) 24
} 
these standards though they are not obliged. ${ }^{1}$ On top of this, the TRIPS Agreement set up standards for limitations and exceptions of copyright against which national laws to be adjudged. Accordingly, article 13 of the TRIPS reads as follows:

'Members shall confine limitations or exceptions to exclusive rights to certain special cases which do not conflict with a normal exploitation of the work and do not unreasonably prejudice the legitimate interests of the right holder.' 2

Brief account of negotiation history might be imperative before embarking to analyze these standards.

Just like the Stockholm negotiations of Berne, the Uruguay round negotiations also faced profound struggle on the issue of an international consensus on limitations to exclusive rights. Once again the negotiators were fascinated by the plurality of limitations. But unlike in the Stockholm negotiations, here the situation was much stressed and strained. Unlike the historical intellectual property bargain between the right holders and users, here the actors for effective bargaining were developed countries with their demand for stronger protection and developing ones for more flexible standards to meet their domestic demands. Thus the balancing process was a dual task - one at the traditional level of right holders and users and the other at the pioneering level of international arena. A compromise to this twin fold challenge was exacerbated both by the plurality of limitations and also by the array of conflicting national interests... Consequently when an international attempt of standardization was made, the only clue left for TRIPS negotiators was the "Three Step Test" (TST) developed in the Stockholm revision of Berne. ${ }^{3}$

Therefore, the origin of the TRIPS standards for copyright limitations, which enshrined under article 13 and commonly called 'three-step test', traces back to the Berne Convention (1967). Article 9(2) of Berne is repeated in Article 13 of TRIPS, with respect to all rights, not only the right of reproduction. 'The test articulated in article 9(2) of the Berne was relatively obscure till 1994; that year, with the adoption of the WTO TRIPS Agreement, it became the cornerstone for almost all exceptions to all intellectual property rights in international law.' ${ }^{4}$ However, it does not mean that TRIPS' TST is totally carbon copy of that of the Berne convention; it makes slight modification besides widening scope of application.

To get full insight about the TRIPS standards for copyright limitations, brief discussion of the three-step test is very crucial. To this end, the WTO Panel decision on case brought in June 2000 between the EC and the US will be prominently useful. The dispute concerned section 110(5) of the US Copyright Act as amended by the Fairness in Music Licensing Act enacted on 27 October 1998. The provision permitted the public performance or display of musical works delivered via a broadcast in certain retail and food or drinking establishments, subject to size and audio-visual equipment limitations. In fact, the section was divided into two parts. The first retained the original exemption allowing display of a work on a single receiving device but was restricted to a very narrow type of work referred to as the "home-style" exemption. The second was a much broader provision exempting retail and food and drinking establishments that complied with certain specified size and audio-visual equipment restrictions from copyright infringement when displaying a transmission of non-dramatic musical works referred to as the "business"' exemption. ${ }^{5}$ According to the panel decision, the three requirements of TST are independent and cumulative that shall be observed all in all. Having said this much, let's see requirements of the three-step test one by one.

\section{A. Certain special case}

Article 13 of the TRIPS requires contracting states to confine limitations or exceptions to the exclusive right to 'certain special cases'. The WTO Panel, in United States- Section 110 (5) of the US Copyright Act, took ordinary meaning of each words of the phrase, 'certain special cases'. To start with, 'certain' means 'known and particularized, but not explicitly identified', 'determined, fixed, not variable; definitive, precise, exact'. This implies that, according to this first requirement of the first test, although an exception or limitation in domestic legislation has to be clearly defined, identification of every possible scenarios to which the limitation could apply does not necessarily required. Still the scope of the limitation shall be known and particularized. The objective pursued by employing this term is to guarantee a sufficient degree of legal certainty. ${ }^{6}$ The continental European tradition where the legislature provides limited list of exceptions will easily fulfill this requirement whereas the common law tradition with an open ended 'fair use' or 'fair dealing' doctrine is vulnerable to serious questions as to their compatibility. ${ }^{7}$

The TRIPS Agreement, Article 1.

Emphasis added.

Exceptions and Limitations to Patent and Copyright under the TRIPS Agreement, 208-209, available at $<$ https://shodhganga.inflibnet.ac.in/bitstream/10603/7993/12/12 chapter\%207.pdf $>$ accessed on 25 March, 2020.

4 Daniel J. Gervais, 'Making Copyright Whole: A Principled Approach to Copyright Exceptions and Limitations' ((2008) 5:1\&2 UOLTJ 1), 24-25.

5 Exceptions and limitations (n 21), 215.

${ }^{6}$ United States-Section 110 (5) of the US copyright Act, Report of the Panel, (World Trade Organization, 2000, WT/DS160/R, Para 6.108), available $@<$ https://www.wto.org/english/tratop_e/dispu_e/1234da.pdf $>$

7 Biruk Haile (n 9) 168. 
The term 'special', which is the second requirement of the first test, is defined as 'having an individual or limited application or purpose', 'containing details; precise, specific', 'exceptional in quality or degree; unusual; out of the ordinary' or 'distinctive in some way'. That means what needed is beyond a clear definition per the first condition. Further, an exception or limitation must be limited in its field of application or exceptional in its scope; it should be narrow in quantitative as well as qualitative sense. ${ }^{1}$ By and large, the panel affirmed that an exception or limitation should be the opposite of a non-special, i.e., a normal case.

However, some scholars argued that this term is defined by the panel incoherently. The phrase, 'limited in its field of application' is not equivalent with its counterpart phrase 'exception in its scope'; and both of them do not necessarily imply quantitative and qualitative narrowness. This definition renders the requirement ineffective since any exception short of complete repeal of Copyright Act would arguably be 'limited in its field of application'. The argument goes to the extent of saying that the three-step test is actually relegated to the twostep test because the first test, 'certain special case', is disregarded. ${ }^{2}$ But this approach could be questioned seriously if one tests it against the extended tradition of construction of the Panel that not to resort to technique of interpretation that yields redundancy or inutility. "It is still possible to understand the first requirement as referring to diminution of the right itself than the economic effect of exception (i.e., non-economic test), which has to be weighed against the second and third tests.' 4

In the panel's view, the ordinary meaning of the term 'case' refers to an 'occurrence, circumstance, event or fact'. In the context of the dispute at hand, the panel stated that the 'case' could be described in terms of beneficiaries of the exceptions, equipment used, types of works or by other factors. ${ }^{5}$ Summarily, the penal argued that a limitation or exception in national legislation should be clearly defined and should be narrow in its scope and reach in order to fulfill the first condition of the TST. This condition does not concern with legitimacy or underlying public policy purpose of the legislation but it may helpful for making inferences about the scope of a limitation or exception or the clarity of its definition. ${ }^{6}$ Taking this interpretation into account, the panel ruled that the business exemption does not qualify this first condition of the TST while the home-style exemption is confined to certain special case. ${ }^{7}$

\section{B. Not conflict with a normal exploitation of the work}

Here also the panel investigated the ordinary meaning of the words, 'normal' and 'exploitation/exploit'. The ordinary meaning of the term 'exploit' connotes 'making use of' or 'utilizing for one's own ends'. As a result, the panel believed that 'exploitation' of musical works thus refers to the activity by which copyright owners employ the exclusive rights conferred on them to extract economic value from their rights to those works. ${ }^{8}$

Likewise, the word 'normal' was defined as 'constituting or conforming to a type or standard', and as 'regular, usual, typical, ordinary, conventional...' In the panel's view, these definitions reflect two connotations; the former definition implies normative approach whereas the latter one entails empirical nature. And the panel intended to develop harmonious interpretation that accommodates both connotations of the term 'normal'. Accordingly, it enunciated that normal exploitation clearly means something less than full use of an exclusive right because equating normal exploitation with full use of exclusive right makes exception under article 13 pointless. 'This is said to be an approach that takes into account only present modes of exploitation and excludes potential modes of exploitation. ${ }^{10}$ Conversely, the normative approach comprises potential modes of utilization that have not been common or normal empirically. ${ }^{11}$ But the approach may turn the exception into worthless because the condition sweepingly cover all possibility of deriving profit from protected subject matter. Instead, amendment of the laws when such conflict actually arises would have been better. On this issue, Dr. Biruk argued that '...whatever superior (non-economic) explanations a country may invoke (for example promotion of education, research, freedom of expression etc) any limitation that enters into economic competition with the right holder will not be tolerated. ${ }^{\prime 2}$ On top of considering actual as well as potential effects of exploitation, this second condition/test has to be tested against each exclusive right irrespective of its positive or negative outcome on other exclusive rights.

To sum up, as reasoned out by the panel, an exception or limitation to an exclusive right in domestic legislation rises to the level of a conflict with a normal exploitation of the work if uses, that in principle are

\footnotetext{
United States-Section 110 (5) of the US copyright Act (n 24) Para 6.109.

2 Biruk Haile (n 9) 169-70, citing Daniel J. Gervais, 'Toward and new Core International copyright Norm: The Reverse Three-Step Test', (2004), 17.

ibid.

4 ibid.

United States-Section 110 (5) of the US copyright Act (n 24) Para 6.110

ibid Para 6.112.

ibid Para 6.133, 145, 159.

ibid Para 6.165.

9 ibid Para 6.166-67.

${ }^{10}$ Biruk Haile (n 9) 171

1 ibid 172.

2 ibid 173.
} 
covered by that right but exempted under the exception or limitation, enter into economic competition with the ways that right holders normally extract economic value from that right to the work and thereby deprive them of significant or tangible commercial gains. Finally, the panel decided that the business exemption ${ }^{1}$, embodied in subparagraph (B) of Section 110(5), conflicts with a normal exploitation of the work whereas the home-style exemption ${ }^{2}$, contained in subparagraph (A) of the section, does not conflict with a normal exploitation of works within the meaning of the second condition/test of the TST.

\section{Not unreasonably prejudice the legitimate interests of the right holder}

In order to fully respond the essence of this condition or test the panel pursued several steps. Literally it said that "first, one has to define, what are the "interests" of right holders at stake and which attributes make them "legitimate"? Then, it is necessary to develop an interpretation of the term "prejudice" and what amount of it reaches a level that should be considered "unreasonable". ${ }^{3}$ The ordinary meaning of the term 'interests' may encompass a legal right or title to a property or to use or benefit of a property. It may also refer to a concern about a potential detriment or advantage. Accordingly, the notion of 'interests' is not necessarily limited to actual or potential economic advantage or detriment. The term 'legitimate' relates to lawfulness from a legal positivist perspective, but it has also the connotation of legitimacy from a more normative perspective, in the context of calling for the protection of interests that are justifiable in the light of the objectives that underlie the protection of exclusive rights. The ordinary meaning of 'prejudice' also connotes damage, harm or injury. 'Not unreasonable' connotes a slightly stricter threshold than 'reasonable'. The latter term means 'proportionate', 'within the limits of reason, not greatly less or more than might be thought likely or appropriate', or 'of a fair, average or considerable amount or size'.

The panel considered that the legitimate interest is the economic value of the exclusive rights conferred by copyright on their holders, admitting that it is not necessarily limited to economic value. By the way, the TRIPS Agreement employs 'the right-holder' instead of 'the author', which used by the Berne convention. Seemingly, this emanates from lack of moral rights recognition as per article 9 (1) of the TRIPS. Then, the panel concluded that prejudice to the legitimate interests of right holders reaches an unreasonable level if an exception or limitation causes or has the potential to cause an unreasonable loss of income to the copyright owner. ${ }^{4}$ That means, 'TRIPS allows exceptions to exclusive rights that prejudice the legitimate interest of the right holder as long as such prejudice is reasonable.' ${ }^{5}$ The panel decided that home-style exemption does not unreasonably prejudice the legitimate interests of the right holder but the business exemption does not meet requirements of this third condition of the TST. ${ }^{6}$ Dr. Guibault noted the relationship between the second and the third conditions of the TST regarding limitation to the right of reproduction as follows:

Basically, where the normal exploitation of the work is threatened, no reproduction is authorized. If the normal exploitation is not affected, one must still examine whether the reproduction causes an unreasonable prejudice to the interests of the author. Unreasonable prejudice may be avoided by the payment of remuneration under a statutory license. ${ }^{7}$

Overall, after an extensive analysis, the WTO panel decreed that the home-style exemption meets the TRIPS' three-step test. As indicated consistently above, the business exemption that enshrined under subparagraph (B) of Section 110(5) of the US Copyright Act, however, does not comply with the requirements of the TST. ${ }^{8}$ Lastly, one can easily conclude that the three-step test has both restraining and supporting functions to copyright limitations and it is mandatory obligation unlike the copyright limitations that are seemingly optional. In other words, once a contracting party to the TRIPS Agreement opts to domestically enact the limitation(s) it cannot opt out adherence to the three-step test.

\section{III.The System of Copyright Limitations under the Marrakesh Treaty \\ 3.1 Overview of the Marrakesh Treaty}

In June 2013, member states of WIPO gathered in Marrakesh, Morocco, in a Diplomatic Conference to negotiate and conclude an international treaty that will facilitate access to published works for blind persons, VIPs and PWPD. The Diplomatic Conference adopted the Marrakesh Treaty on June 27, 2013. The Treaty has entered into force on September 30, 2016, which is three months after June 30, 2016, the date by which twenty eligible states had deposited instruments of ratification or accession. ${ }^{9}$ The goal of the treaty is to end the book famine - the fact

\footnotetext{
United States-Section 110 (5) of the US copyright Act (n 24) Para 6.211.

ibid Para 6.219.

ibid Para 6.222.

ibid Para 6.227, 229.

5 Biruk Haile (n 9) 175.

${ }^{6}$ United States-Section 110 (5) of the US copyright Act (n 24) Para 6.266, 6.272.

Dr. Lucie Guibault (n 14) 3.

ibid Para 7.1.

${ }^{9}$ ARIPO Guidelines for the Domestication of the Marrakesh Treaty, 7; available at $<$ https://www.aripo.org/wpcontent/uploads/2018/12/>, accessed on 27 March, 2020.
} 
that only about $7 \%$ of published books are made available globally in accessible formats, such as Braille, audio and large print, and DAISY (Digital Accessible Information System) formats. In the developing world, the figure is less than $1 \%$. This situation is partly due to barriers created by copyright law, barriers that the treaty seeks to remove. ${ }^{1}$ It is the first treaty devoted exclusively to creating international minimum standards for the benefit of users of copyright protected materials. ${ }^{2}$

\subsection{The Copyright Limitations under the Marrakesh Treaty 3.2.1 General Remarks}

To start with, the Marrakesh treaty defines beneficiary person broadly. According to article 3 of the treaty, it includes persons who are blind, visually impaired and reading disabled as well as who have physical disability that impedes them to use printed materials. Generically, blind, visually impaired persons (VIPs) and persons with a print disability (PWPD) are exclusive beneficiary of accessible format copy (AFC).

VIP or dyslexic person ranges from only light impairment ... to the inability to read a text without assistive technology. The category of 'print disabled' or 'people with a print disability' also includes persons who are paralyzed and who cannot manipulate a book or e-book. Moreover, there are other visual disabilities that require alternate formats, such as letters highlighted in white or yellow or undulating text or text written in light typeset set against a black page background. ${ }^{3}$

Therefore, the Marrakesh Treaty enunciates limitations and exceptions that solely benefit persons who are unable to use/read printed materials or PWPD. However, even if the Marrakesh treaty focus on PWPD, adoption of copyright exceptions domestically for the benefit of people with other disabilities is possible pursuant to article $12(2)$ of the treaty. ${ }^{4}$

One of the obligations of a contracting state to the treaty is to facilitate the availability of works in AFCs for beneficiary persons. ${ }^{5}$ The beneficiary persons, mentioned above, have right to get AFCs of works. At this juncture, understanding contextually what do 'AFC-accessible format copy' and 'works' mean is imperative to delineate scope of the state's obligations. They are defined under article 2 (a) \& (b) of the treaty. Accordingly, AFC means a copy of a work in an alternative manner or form which gives a beneficiary person access to the work. This includes a manner or form that permits the person to have access to the work as feasibly and comfortably as a person without visual impairment or other print disability. This is also a broad definition that does not limit format or technique of making the work accessible to the beneficiary persons. Whatsoever alternative form or manner can be deemed AFC so long as it ensures accessibility of the work to the persons. Carlo S. Lavizzari has profoundly expressed this issue as follows:

... AFC is a term that needs to be interpreted relative to the individual beneficiary person or the sub-set or types of disability in question, the beneficiary's skill, and the enabling technological environment available to the beneficiary person. It is thus hardly surprising that the MT can only use broad strokes to define AFC in a way that is technology-neutral, and which does not limit the format or the technique used to make a work (more) accessible than the available original publication... ${ }^{6}$

Under the Marrakesh treaty, 'works' are only those works within the meaning of the Berne Convention that have already been published or otherwise made publicly available in any media, and which exist in the form of text, notation and/or related illustrations. This comprises written texts, musical notations and text in audio form (particularly audio books), as elucidated in the agreed statement regarding article 2 (a) of the treaty. But a work, under the treaty, does not include audiovisual works, particularly films. Carlo S. Lavizzari argued that 'textual works embedded in audiovisual works (such as educational multimedia DVDs) would appear to fall within the definition. ${ }^{7}$ Moreover, the work has to be published or made publicly available in any media. The treaty does not allow change of the work's content under the guise of making AFC. Rather it allows merely for the work's contents to be transcribed into an AFC. ${ }^{8}$ The role of an authorized entity, as defined under article 2 (c), is also enormous to make and distribute the AFCs.

\subsubsection{Specific Limitations}

Let's briefly see those exceptions and limitations recognized under the treaty before embarking to its analysis in

\footnotetext{
${ }^{1}$ The Marrakesh Treaty: An EIFL Guide for Libraries (Dec. 2014), 1; available at < $\underline{\text { https://www.eifl.net/sites/default/files/eifl-guide- }}$ marrakesh en 1.pdf $>$, accessed on 15 April, 2020.

2 See for instance, article 2 (b) , 3, 4 (2) (a) (iii) and 5 (2) (a) of the Marrakesh Treaty. But this does not mean that it arguably affects exclusive rights of author/holder more than exceptions and limitations provided under other international copyright treaties. Seemingly it gives clarification to already existing exceptions and limitations but probably between different/additional member states and in obligatory nature.

3 Carlo Scollo Lavizzari, 'IPA Guide to the Marrakesh Treaty', 8; available at $<$ https://www.internationalpublishers.org/images/Accessibility/> accessed on 15 April, 2020.

The Marrakesh Treaty: An EIFL Guide for Libraries (n 47), 6.

The Marrakesh Treaty, Article 4 (1) (a)

Lavizzari (n 49), 15 (emphasis added).

Lavizzari (n 49), 14.

ibid.
} 
light of TRIPS standards. First, there is compulsory limitation to right of reproduction and distribution of copyright holder as to AFC of a work. Accordingly, the contracting parties shall provide limitation to these rights so as to ensure availability of works in AFC. To this end, authorized entities must be permitted to make AFC of a work, without authorization of the copyright holder, and to distribute these copies to beneficiary persons by any means. ${ }^{1}$ Similarly, a beneficiary person may make AFC of a work for his/her personal use provided that he/she has lawful access to the work or copy thereof. A representative of the beneficiary person, primarily caretaker or caregiver, may also make AFC of the work for the latter's personal use or may assist the beneficiary person to make it. ${ }^{2}$ The cumulative requirements, which are enshrined under this sub-article and called by some scholars as "safe harbor", are 'the copy must be for the personal use of the beneficiary', and 'the beneficiary must have lawful access to the work or a copy thereof'. ${ }^{3}$ Optionally, a limitation to the right of public performance to facilitate access to works for beneficiary might be enacted by contracting parties.

Moreover, it is up to national laws of each contracting parties whether or not the limitation under article 4 is compensated.

Arguably the limitation, which enshrined under article 4, could not be invoked when the copyright holder himself has already made AFC and efficiently distributed the copies to the beneficiaries. '... a work that is 'born accessible', meaning a work which consists of printed text only and which may be used from the outset by both sighted and VIPs/PWPDs through a choice of different display options, is not covered by the Marrakesh Treaty. ${ }^{4}$ In fact, article 4 (4) of the treaty allows a state party to narrowly restrict limitations on the works that commercially unavailable under reasonable terms. That means, the state may make reproduction and distribution of AFCs of works an exclusive right of the copyright owner provided that the owner make them commercially available in reasonable terms. But this should be format specific in a sense that limitation has to be still extended concerning commercially unavailable format(s) of a work even if another type of format(s) of the same work is commercially available. ${ }^{5}$ Some scholars urged that states extend exceptions and limitations to all covered works, including works that are commercially available because the term 'commercial availability', for instance, lacks clarity. ${ }^{6}$

Second, cross-border exchange of AFCs shall be permitted by contracting parties if the copies are made under a limitation/exception. To achieve this goal, authorized entities shall be allowed, without the authorization of the right holder, to distribute or make available AFCs to an authorized entity, in another member parties, but for the exclusive use of beneficiary persons. Furthermore, the entities shall also be permitted to distribute or make available AFCs directly to beneficiary persons in another member parties. ${ }^{7}$ Reciprocally, the entities shall be permitted, besides a beneficiary person and his/her representative, to import AFC for the benefit of the beneficiary person, without the authorization of the right holder. ${ }^{8}$ Moreover, the contracting parties shall endeavor to foster the cross-border exchange of the AFC pursuant to article 9 of the treaty. The objective of this limitation is obvious. It guarantees freely exchange of AFCs a cross boundary and thereby avoids costly duplication efforts in various countries by multiple institutions. By and large, institutions with larger collections of AFC may share them with beneficiary persons in countries with fewer resources. ${ }^{9}$ This enables importation of ready-made AFCs from other member parties instead of reproducing the copies locally by incurring unnecessary costs. In particular, foreign donor institutions can easily venture distribution of AFCs abroad, without being constrained by national boundary. Shortly, it paves a way to overcome shortage of AFCs and thereby to realize principles of non-discrimination, equal opportunity, accessibility etc enshrined under UDHR and UNCRPD. Interestingly, article 7 of the treaty imposes additional obligation on contracting parties that give legal protection against the circumvention of technological protection measures (TPMs). Such parties shall take appropriate measures to ensure that the legal protection does not prevent beneficiary persons from enjoying those limitations and exceptions enshrined under the treaty.

\subsubsection{The Strengths and Weaknesses of the Limitations in light of the TRIPS Standards}

Under this section, the TRIPS three-step test will be used as a yardstick to evaluate the copyright limitations under Marrakesh Treaty and thereby reveal strengths and weaknesses of the limitations. The three-step test has been discussed previously. Here the main task is merely to reflect the test on the copyright limitations under the Marrakesh Treaty. The intended goal of the treaty should be undoubtedly taken as a great success indeed.

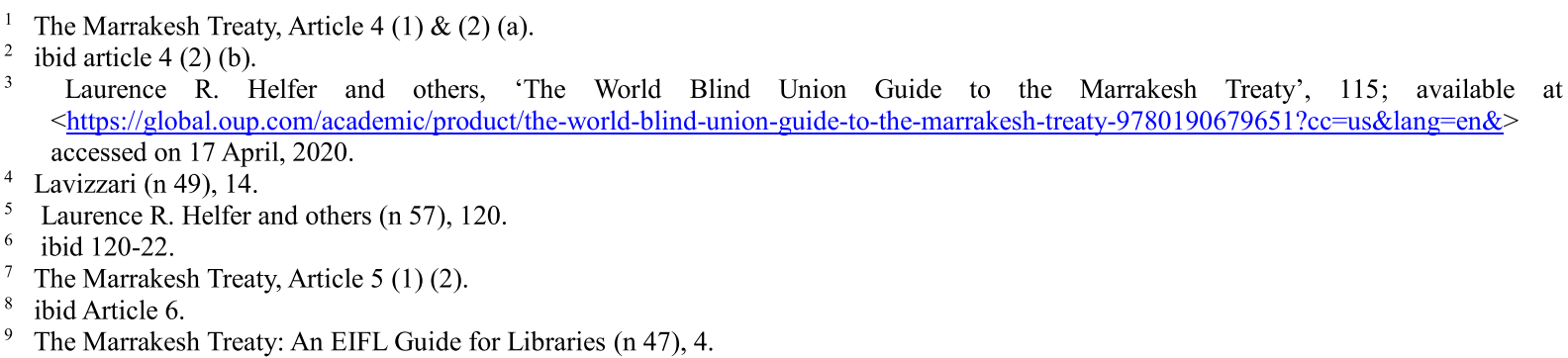


However, in this section strengths and weaknesses will be discerned only from the three-step test point of view.

\section{A. Strengths}

The treaty, article 11, articulates that contracting party shall abide by the obligations which the party has, inter alia, under article 13 of the TRIPS Agreement when taking up measures necessary to ensure the application of the treaty. As mentioned repeatedly before, the TRIPS article 13 caters standards for copyright limitations, commonly known as the three-step test. Thus, article 11 of the Marrakesh treaty requires contracting parties, which subscribed to the TST, to observe the test in course of domestically implementing limitations recognized by the treaty. The preamble of the treaty also reaffirms the obligations of contracting parties under the existing international treaties on copyright protection as well as importance and flexibility of the three-step test. At this juncture, one may conclude that the treaty adheres to, at least roughly, the TRIPS standards for copyright limitations and this can be reckoned as strength. Still some scholars, by looking it from intended objectives of the treaty, consider this allegiance of the treaty to the three-step test as its weakness. ${ }^{1}$ However, setting aside whether or not the intended aims would be genuinely achieved in such manner, synchronization of the treaty with the three-step test is vitality; glimpsing solely of the standards at hand.

Nevertheless, there is divergence among scholars regarding application of article 11 of the treaty. Prof. Martin Senftleben argued that the Marrakesh treaty conflates very specific rules on limitations for beneficiary persons with blurred standards of the three-step test under the TRIPS article 13. Articles 4 and 5 of the treaty contains not only general obligation to adopt specific limitations but also exemplary provisions. The open-ended three-step test is used as general yardstick to determine the permissibility of these and others specific limitations. 'The three-step test was thus added as a complicating and destabilizing factor that reduces the legal certainty which the adoption of precisely-defined L\&Es would otherwise have guaranteed. ${ }^{3}$ As a result, the primary objective of the treaty is compromised and even, '...the whole system of precisely-defined limitations and exceptions established in the Marrakesh is in danger of becoming dysfunctional...' ${ }^{4}$ Doubtfully, supporting function of the three-step test that reconciles copyright protection with competing social, cultural and economic interest is disregarded by the Marrakesh treaty concerning articles 4 (2) and 5 (2). Rather its constraining function is opted for. ${ }^{5}$

On the other hand, others argued that articles 4 (2), 5 (2) and 6 of the Marrakesh treaty create "safe harbor" in a sense that these provisions presumptively fulfill requirements of the three-step test. ${ }^{6}$ In other words, the provisions have already adopted the essence of the TST; and no need of redundantly evaluating them in light of the test. Accordingly, Sui generis approach limitations and exceptions such as articles 4 (3) and 5 (3), which might be enacted discretionally by contracting parties, shall comply with conditions of the three-step test. ${ }^{7}$ Hence, article 11 of the treaty contemplates such sui generis approach limitations rather than those which create "safe harbor".

The other strength of the system of copyright limitations is that it provides substantially mandatory and clear limitations. Conversely, limitations of copyright under TRIPS are optional and ambiguous. ${ }^{8}$ To ensure the users benefit effectively, limitations of copyright under the Marrakesh treaty are considerably articulated in mandatory and clear manner. ${ }^{9}$ To cite, articles 4 (1), 5 (1), 6 and 7 of the treaty provide compulsory limitations and exceptions that contracting parties shall endorse and implement domestically. Still there are few limitations that are optional like that of the TRIPS. For instance, making law that limits the right to public performance of works becomes discretionary one. Moreover, some copyright limitations under the treaty contain exemplary provisions along with specific rules. This might be considered as an extension of clarity and specificity of the limitations. For instance, articles 4 (2) and 5 (2) enclose indications that may be adopted by a contracting party to fulfill its obligations under sub-article 1 of the articles. This is quite important to ensure uniform and harmonized implementation a cross contracting parties. The exemplary provisions can be considered as guidelines/models that probably espoused by all members because their essence is almost conditions of the TST although it seems optional terminologically. Hence, this can also be counted as one of the strengths the system.

\section{B. Weaknesses}

As discussed above, the system of copyright limitations under the Marrakesh treaty have a lot of strengths. Still there are a few weaknesses that would have been rectified in order to properly attain intended objectives without violating the TST. First, there is lack of clarity as to application of the three-step test via article 11 of the treaty.

\footnotetext{
Martin Senftleben, 'A Copyright Limitations Treaty Based on the Marrakesh Model: Nightmare or Dream Come True?' (SSRN Electronic Journal, 2017), 1-3.

ibid, $1-3,16$

ibid 8 .

ibid 4

ibid 4, 8-9, 12

Laurence R. Helfer and others (n 57), 112-15, 163-64.

ibid 117.

See the TRIPS Agreement, article 13.

The Marrakesh Treaty, articles 4 (1) (a), 5 (1), 6 \& 7.
} 
Whether or not article 11 of the treaty applies on all limitations for beneficiary persons, without distinction, is still not settled safely. As stated somewhere above, some of copyright limitations under the treaty are more specific and roughly contain conditions of the three-step test. There are also provisions of the treaty that make direct reference to article 11. Article 4 (3) and 5 (3) of the treaty can be taken as example. But wording of the article 11 does not explicitly make distinction between limitations under the treaty; it simply says partly, 'in adopting measures necessary to ensure the application of this treaty...' However, applying the three-step test on those specific limitations, which also contain exemplary provisions, amounts to scrutinizing twice and making them dysfunctional at all. ${ }^{1}$ The fact that three-step test is blurred concept may highly exacerbate this issue. That is why, some scholars try to exonerate such limitations from re-assessment in light of the three-step test, arguing that the limitations has already created "safe harbor". ${ }^{2}$ Nonetheless, had the article 11 of the treaty been articulated clearly, various interpretation would not be raised to avoid absurdity.

Second, a contrario reading of article 4 (4) suggests that contracting parties may extend limitations to works irrespective of their commercial availability under reasonable terms. That means, limitation may be provided to reproduction and distribution right of an author even if AFC of his/her work is commercially available under reasonable terms. Preamble of the treaty expresses as the treaty recognizes the importance of right holders role in making their works accessible to beneficiary persons. Equally, it recognizes the importance of appropriate limitations and exceptions to make works accessible to the persons, particularly, when there is market failure. As glimpsed previously, market dysfunction is one of the justifications for copyright limitations. The limitations are probably deemed appropriate, according to the preamble, if market failure or other justification necessitates them. However, article 4 (4) permits the contracting parties even to apply limitations on works that are commercially available under reasonable terms. Perhaps this will violate the second and/or third conditions of the three-step test. Because such limitations are more likely conflict with normal exploitation of the works and/or unreasonably prejudice the legitimate interest of the right holder unless the provision is narrowly construed in line of the preamble. Incidentally, lack of clarity about what constitutes 'commercial availability' and 'reasonable term' might practically worsen the matter.

Thirdly, discretion is given again to national laws of contracting parties to determine whether or not limitations and exceptions as to creation, distribution or making available AFCs of will be compensated. ${ }^{3}$ In other words, contracting parties are at liberty to make all limitations or some of them uncompensated, without payment of a royalty or other license fee to the copyright holder. If so, violation of the second and/or third conditions of the three-step test might happen here too. In fact, the provision contemplated pre-existing remuneration required laws in some countries but preferred to sustain this status quo. ${ }^{4}$ Although the scholarly argument that 'widely-adopted remuneration requirement would impede' ${ }^{5}$ intended goals of the treaty is quiet convincing, equally widely-adopted non-remuneration requirement may downside, and likely to contravene with, the three-step test.

\section{IV.Conclusions and Recommendations \\ 4.1 Conclusions}

The system of copyright limitations, as integral part of the copyright system, is developed to ensure benefit of users of copyrighted materials. There are various justifications for the copyright limitations. Internationally, three-step test is a well known standard for the copyright limitations. The TRIPS Agreement, article 13, espouses the three-step test. Accordingly, the copyright limitations (1) should be clearly defined and narrow in its scope and reach; (2) should not compete with the ways the right holders normally extract economic value from the work and thereby deprive them significant commercial gains, and (3) should not cause or have the potential to cause an unreasonable loss of income to the copyright owner. Looking at the Marrakesh Treaty, which was adopted in 2013 as copyright limitations for exclusive benefit of blind persons, VIPs and PWPD, is attempted in light of the TRIPS' TST to identify strengths and weaknesses of the treaty. In addition to the general acknowledgement of compliance to the TRIPS' TST, there are specific, exemplary and clear conditions that are enshrined in some provisions of the treaty and presumed satisfying the requirements of the TST. On the other hand, lack of clarity about the application of the TST as well as giving discretionary power to contracting parties to extend the limitations to works commercial available and to make the limitations uncompensated, without providing necessary preconditions, may be considered as weaknesses.

\subsection{Recommendations}

The system of copyright limitations, as integral part of the copyright system, is developed to ensure benefit of

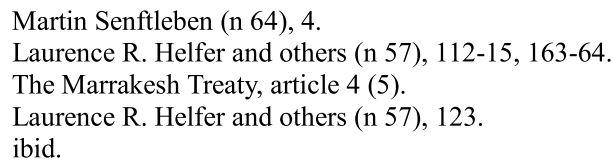


users of copyrighted materials. There are various justifications for the copyright limitations. Internationally, three-step test is a well known standard for the copyright limitations. The TRIPS Agreement, article 13, espouses the three-step test. Accordingly, the copyright limitations (1) should be clearly defined and narrow in its scope and reach; (2) should not compete with the ways the right holders normally extract economic value from the work and thereby deprive them significant commercial gains, and (3) should not cause or have the potential to cause an unreasonable loss of income to the copyright owner. Looking at the Marrakesh Treaty, which was adopted in 2013 as copyright limitations for exclusive benefit of blind persons, VIPs and PWPD, is attempted in light of the TRIPS' TST to identify strengths and weaknesses of the treaty. In addition to the general acknowledgement of compliance to the TRIPS' TST, there are specific, exemplary and clear conditions that are enshrined in some provisions of the treaty and presumed satisfying the requirements of the TST. On the other hand, lack of clarity about the application of the TST as well as giving discretionary power to contracting parties to extend the limitations to works commercial available and to make the limitations uncompensated, without providing necessary preconditions, may be considered as weaknesses. 